\title{
Distribution of crab larvae in relation to tidal fronts in Delaware Bay, USA
}

\author{
M. Clancy, C. E. Epifanio \\ College of Marine Studies, University of Delaware, Lewes, Delaware 19958, USA
}

\begin{abstract}
Replicate observations of hydrographic structure and crab larval distributions were conducted at ebb-tide, flood-tide and non-frontal sites in lower Delaware Bay. Results show that frontal structure is restricted to the upper $2 \mathrm{~m}$ of the water column and that convergent velocities associated with the fronts are sufficient to collect buoyant and upward-swimming plankton at the surface. Despite this, maximum concentrations of larvae at fronts were found at depths greater than the frontal pycnocline, while larvae at the non-frontal site showed no significant difference in their abundance with depth. While the observed frontal distributions may be due to a balance between upward swimming by the larvae and downward movement of water at the frontline, ecological effects are mitigated by the ephemeral nature of the fronts.
\end{abstract}

\section{INTRODUCTION}

Surface fronts are sloping boundaries between 2 water masses of different density. In moderate sea states, the intersection of this boundary and the water surface is visible as a color discontinuity or as an accumulation of foam; this is termed the front line. The horizontal extent of a front line may exceed $10^{3} \mathrm{~km}$ in persistent oceanic fronts or may be restricted to less than $10 \mathrm{~km}$ in estuarine tidal fronts. Regardless of scale, circulation associated with these fronts is always characterized by a sinking of heavier water as it encounters a mass of lighter water at the frontal boundary, i.e. at the pycnocline (Garvine 1974). Friction at the pycnocline carries lighter water along in this sinking process, and a general downwelling, including associated convergent surface currents, is established at the front line.

Frontal circulation can have important effects on the plankton because the convergent surface currents may carry organisms from either side of the front to the region of downwelling. Those organisms that are buoyant or that tend to swim upward in the water column may be concentrated at the surface near the front line. Indeed, earlier investigations have shown that planktonic organisms accumulate along these fronts in both the open ocean (Fournier et al. 1979) and in estuarine and adjacent coastal waters (Pingree et al. 1978, Tyler \& Sliger 1978, Tyler et al. 1982, Zeldis \& Jillett 1982, Chin-Leo 1985). Once concentrated in these frontal regions, planktonic organisms are exposed to conditions of food availability, predator exposure, and horizontal advection that can be very different from those experienced by plankton in non-frontal areas.

Estuarine fronts may form as a consequence of a large influx of fresh water spreading over a more saline layer (Garvine \& Monk 1974), from the influence of a geomorphological structure (Pingree et al. 1978), or as a consequence of tidal circulation in the estuary (Simpson \& Hunter 1974, Huzzey \& Brubaker 1988). Fronts most commonly occurring in the large estuaries of the Middle Atlantic Bight are the result of tidal processes. These tidal fronts are shallow structures with pycnocline depths of no greater than a few meters (Sarabun 1980), and they are often found over shoals where tidally generated bottom turbulence is sufficient to break down vertical stratification on the shallow side of the front (Simpson \& Hunter 1974, Bowman \& Iverson 1978).

In this paper, we present results from an intensive investigation of crab larval distributions adjacent to tidal fronts in Delaware Bay, USA. The study is unique in that replicated observations from 2 frontal regions are compared to similar observations in non-frontal area.

Before undertaking this investigation, we conducted an aerial survey to determine the location and duration of tidal fronts in lower Delaware Bay (Fig. 1). Overflights were made every $2 \mathrm{~h}$ throughout one complete tidal cycle at ca $300 \mathrm{~m}$ altitude. Fronts were photographed 


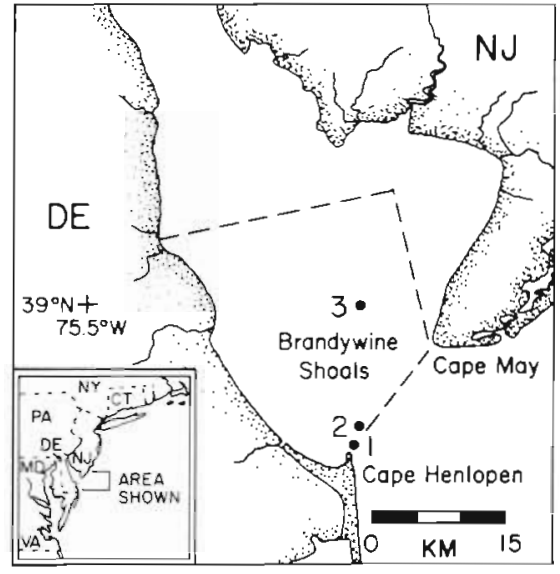

Fig. 1. Location of stations where crab larvae were collected in association with tidal fronts in Delaware Bay, USA. Stn 1 was an ebb-tide site; Stn 2 was a non-frontal site; Stn 3 was a flood-tide site. Dotted line shows boundaries of a preliminary aerial survey of frontal location and duration

and location, spatial extent, and tidal phase were recorded on audio tape. Results of this survey indicated that: (1) fronts form during both ebb and flood tides, but they are not coherent over a full tidal cycle, and (2) both flood-and ebb-tide fronts are aligned parallel to the northwest-southeast orientation of the bay

\section{MATERIALS AND METHODS}

Replicate field observations. Three sets of replicate field observations were conducted: (1) ebb-tide front off Cape Henlopen in the mouth of Delaware Bay, (2) flood-tide front ca $20 \mathrm{~km}$ upstream near Brandywine Lighthouse, and (3) non-frontal site near Cape Henlopen (Fig. 1), Location of these fronts was based on results of the preliminary aerial survey

By employing 2 research vessels, it was possible to complete 5 sets of replicate physical and biological measurements within $2.5 \mathrm{~h}$ at each site. Before initiating measurements at a given site, 6 surface drifters (orange plywood squares) were deployed on either side of the front for along an arbitrarily selected line at the non-frontal site) ca $50 \mathrm{~m}$ from the front line. At the frontal sites the drifters were advected rapidly in to the front, thus demonstrating convergent circulation.

A replicate hydrographic measurement consisted of 5 equidistant CTD casts made along a $200 \mathrm{~m}$ transect perpendicular to the front. The mid-point in each transect was in the front line, and each transect extended $100 \mathrm{~m}$ to either side of the front line. Five replicate hydrographic measurements were made at each study site. A Seabird Electronics CTD was used at the ebbtide and non-frontal sites, while a Beckman RS-5 CST meter was employed at the flood-tide site.
Plankton tows were made during daylight hours with $1 \mathrm{~m}, 335 \mu \mathrm{m}$ mesh cinch nets that could be opened and closed as discrete depths. Water volume sampled by the net was measured with a TSK flow meter mounted in the mouth. For each study site, a replicate consisted of one sample taken at each of 4 sampling regions (see inset in Fig. 2B). Tows in Sampling Regions 1 and 2 (SR1 and SR2) were taken ca $5 \mathrm{~m}$ from the front line with SR3 and SR4 directly beneath them. All tows were taken parallel to the front line. Towing depths were $1 \mathrm{~m}$ in SR1 and SR2 and $5 \mathrm{~m}$ in SR3 and SR4. This procedure was repeated 5 times at each frontal site coincident with hydrographic measurements. An identical procedure was followed along an arbitrary line at the nonfrontal location. In all cases samples were preserved on deck in $4 \%$ buffered formaldehyde solution and returned to the laboratory for later analysis.

The ebb-tide front was sampled on August 5, 1987, while the flood-tide observations were conducted on September 16, 1987. The non-frontal site was sampled on August 6, 1987

Sites-of-opportunity. As an adjunct to a large ichthyoplankton survey, we were able to sample tidal fronts at 9 sites-of-opportunity in a large area of lower Delaware Bay during a $7 \mathrm{wk}$ period in late summer 1987. Prospective fronts were identified by foam or color lines at the surface. At each prospective front, one CTD cast was taken on either side of the front line, using a Beckman RS-5 CST meter. Measurements were recorded every $0.5 \mathrm{~m}$ above and every $1 \mathrm{~m}$ below the pycnocline down to the bottom. Once it was ascertained that a prospective front had the physical characteristics of a tidal front, one plankton sample was taken in each of the 4 sampling regions as above.

Analysis of larval abundance. In the laboratory, plankton samples were transferred from formaldehyde to $70 \%$ ethanol, and crab larvae were identified according to Sandifer (1975). Dense samples were split with a Folsom plankton splitter before analysis.

For each of the replicated sampling regimes, mean larval abundance relative to the pycnocline was compared by Kruskal-Wallis analysis (Sokal \& Rohlf 1981). This non-parametric test was used due to a heterogeneity of variances in each of the data sets. A posteriori comparisons among treatments (sampling regions) were made with a Tukey-analogue multiplecomparisons test ( $Z$ ar 1984). Inference was always made at $\alpha=0.05$.

Hydrographic data analysis. A contour plot of the vertical distribution of density $\left(\sigma_{t}\right)$ was made along each transect. All densities for the ebb-tide and nonfrontal sites were obtained by the Seabird CTD. Densities from the flood-tide site were calculated from salinity and temperature (Beckman RS-5 CST meter) according to formulae given by Knauss (1978). Conver- 


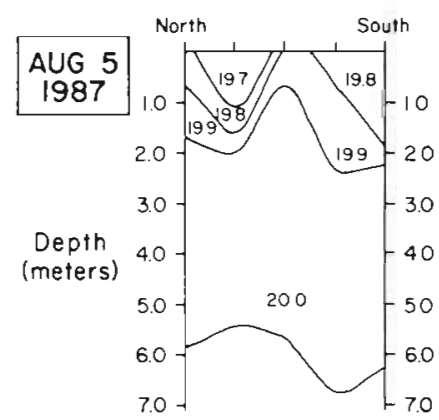

A
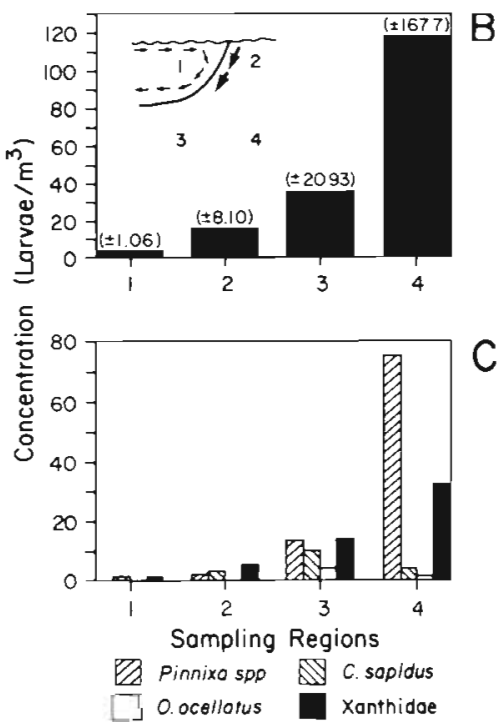

Fig. 2. Physical and biological characteristics of an ebb-tide site near Cape Henlopen at the mouth of Delaware Bay, USA. (A) Vertical distribution of density along a $200 \mathrm{~m}$ transect perpendicular to front line. (B) Mean abundance of crab zoeae in 4 sampling regions near front line. Inset shows location of regions relative to frontal pycnocline. Values in parentheses are standard deviations. (C) Mean abundance of crab zoeae by taxon

gent velocities of all fronts $(u)$ were estimated using a modified shallow-wave speed equation (Garvine 1974):

$$
u \approx \sqrt{(\bar{g} d)}
$$

where $g^{\prime}$ (reduced gravity) $=\Delta \rho / \rho g_{i} \Delta \rho=$ difference in water density $\left(\mathrm{g} \mathrm{cm}^{-3}\right)$ across the pycnocline at the surface; $\rho=$ density of the heavier water; $g=$ acceleration due to gravity $\left(980 \mathrm{~cm} \mathrm{~s}^{-2}\right)$; and $d=$ depth of the pycnocline $(\mathrm{cm})$.

\section{RESULTS}

\section{Replicate field observations}

At the ebb-site, denser shelf water was located to the southwest of the front toward Cape Henlopen (Fig. 2). The mean surface density difference across the front was $0.2 \sigma_{t}$ units; this combined with a pycnocline depth of $200 \mathrm{~cm}$ resulted in a calculated convergent velocity of $6 \mathrm{~cm} \mathrm{~s}^{-1}$. Kruskal-Wallis analysis showed a significant $(\mathrm{df}=3 ; p=0.002)$ difference in overall larval abundance in the 4 sampling regions, and Tukey-analogue multiple-comparisons analysis found no significant difference between SR4 and SR3 or between SR2 and SR1.

Pinnixa spp. and several taxa in the family Xanthidae dominated the larval assemblage and comprised $95 \%$ of all larvae caught. Of the remaining larvae, only Callinectes sapidus and Ovalipes ocellatus occurred at

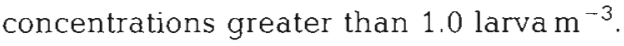

Frontal structure was more highly defined at the flood-tide location (Fig. 3). A change of ca $1.0 \sigma_{t}$ unit across the front and a $180 \mathrm{~cm}$ deep pycnocline produced a convergent velocity of $13 \mathrm{~cm} \mathrm{~s}^{-1}$. Larval abundance was again greatest in SR3 and SR4. However, Kruskal-Wallis analysis indicated no significant difference ( $\mathrm{df}=3 ; p=0.8$ ) in the 4 sampling regions. The flood front was sampled late in the spawning season, and although the dominant taxa still included Pinnixa spp., Ovalipes ocellatus, and some xanthid species, concentrations were an order of magnitude less than those seen at the ebb front.

The water column at the non-frontal site was typical of lower Delaware Bay (Epifanio 1988) and showed
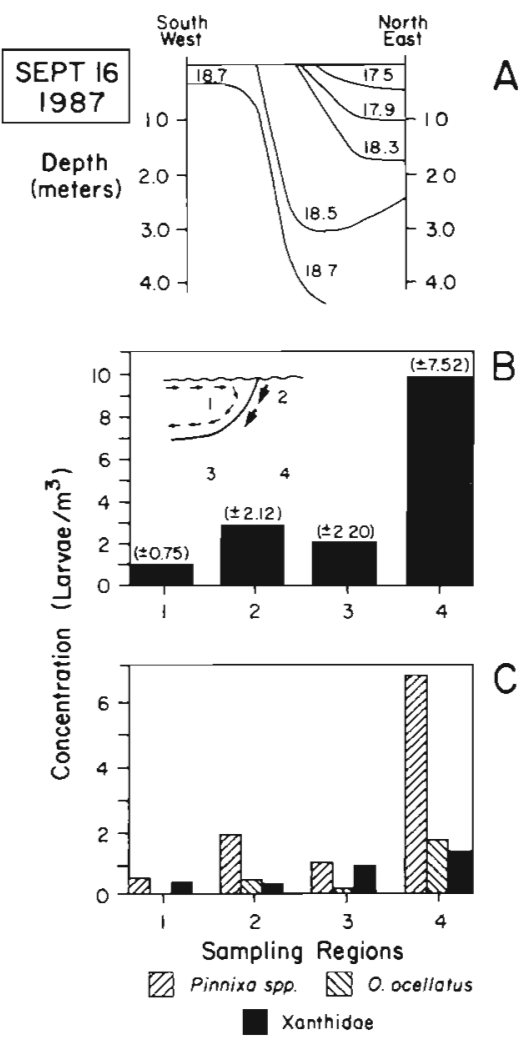

Fig. 3. Physical and biological characteristics of a flood-tide site near Brandywine Lighthouse in Delaware Bay, USA. Legend as for Fig. 2 

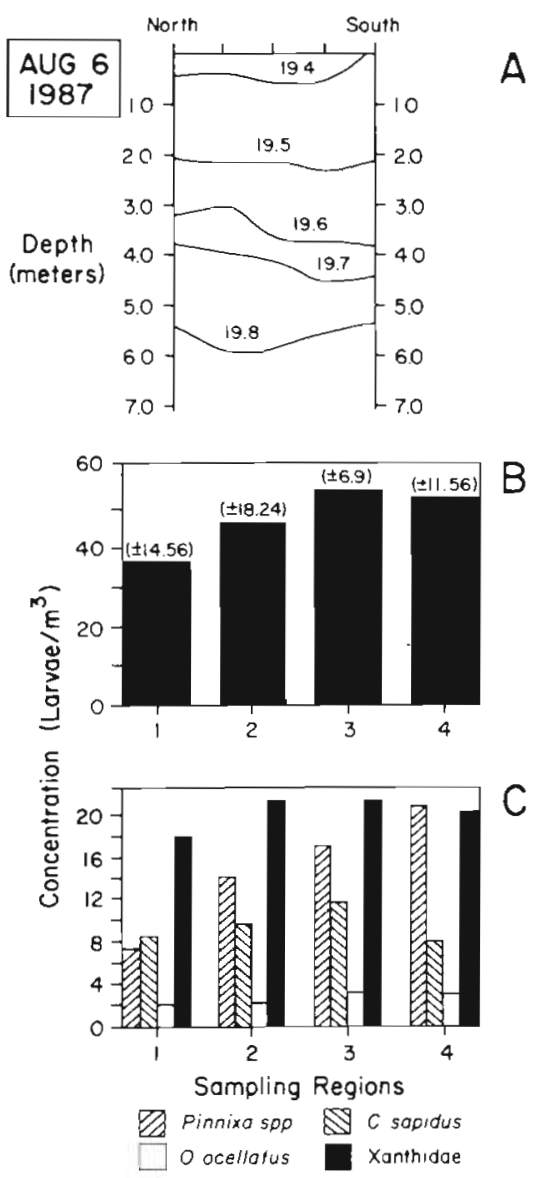

Fig. 4. Physical and bjological characteristics of a non-frontal site near Cape Henlopen at the mouth of Delaware Bay, USA. Legend as for Fig. 2

horizontal isopycnals with a gradual increase in density from surface to a depth of $5 \mathrm{~m}$ (Fig. 4). There was no significant ( $\mathrm{df}=3 ; p=0.28$ ) difference in larval abundance among the 4 sampling regions. As in the nearby ebb-tide site, Pinnixa spp., Callinectes sapidus, Ovalipes ocellatus, and several xanthid species were the most abundant taxa. This similarity in dominant taxa is not surprising as the sites were sampled on identical tidal phases (ebb) on consecutive days.

\section{Sites-of-opportunity}

Both ebb-tide and flood-tide fronts were sampled during a $7 \mathrm{wk}$ period. Calculated convergent velocities ranged from 2 to $11 \mathrm{~cm} \mathrm{~s}^{-1}$ (Table 1). Because of large temporal and spatial differences in absolute abundance, the abundance of larvae in each sampling region was always normalized as a percentage of the total number of larvae collected at a given front. Generally the distribution of larvae at these fronts was similar to that oberved at the replicated sites above.
Table 1. Abundance of crab zoeae in 4 sampling regions near tidal fronts in Delaware Bay, USA. Depth of sampling was $1 \mathrm{~m}$ in Regions 1 and 2 and $5 \mathrm{~m}$ in Regions 3 and 4 . Abundance values are percentage of total catch at each front. Convergent velocity in $\mathrm{cm} \mathrm{s}^{-1}$. E: ebb tidal front; F: flood tidal front. More than one front was sampled on September 2 and September 29

\begin{tabular}{|lccrrrr|}
\hline Date & Tide & $\begin{array}{c}\text { Convergent } \\
\text { velocity }\end{array}$ & \multicolumn{4}{c|}{ Sampling region } \\
& & & 1 & 2 & 3 & 4 \\
\hline Aug 13 & E & 5 & 2 & 1 & 18 & 79 \\
Sep 11 & E & 4 & 8 & 1 & 72 & 19 \\
Sep 29 & E & 9 & 21 & 11 & 18 & 50 \\
Sep 29 & E & 6 & 18 & 6 & 44 & 32 \\
Sep 2 & F & 11 & 4 & 18 & 28 & 50 \\
Sep 2 & F & 6 & 1 & 7 & 66 & 26 \\
Sep 10 & F & 2 & 10 & 10 & 43 & 37 \\
Sep 29 & F & 6 & 2 & 4 & 36 & 58 \\
Sep 29 & F & 6 & 0 & 1 & 95 & 4 \\
\hline
\end{tabular}

\section{DISCUSSION}

The results of this research show that convergent velocities associated with tidal fronts in Delaware Bay are sufficient to collect buoyant and upward-swimming plankton at the surface. Despite this, brachyuran crab larvae were never found in greatest abundance at the surface near the front line. Instead, maximum abundance occurred consistently below the pycnocline. This pattern of abundance was invariable throughout the study period and was statistically significant for replicated observations at an ebb-tide site near Cape Henlopen. While earlier investigations have reported highest abundance of zooplnakton directly in the front line at the surface (Klemas \& Polis 1977, Sick et al. 1978), the frontal pycnocline forms a sharp boundary (Sarabun 1980), and hydrographic measurements only a few meters on either side of the front line show very distinct water masses (Figs. 2 and 3). Additionally, surface and aerial observations in the present study show that the front line tends to meander with an approximate amplitude of 1 to $10 \mathrm{~m}$. Thus, any attempt to tow a plankton net directly in the front line results in an amalgamated sample from water masses on elther side of the front, and published estimats of plankton abundance directly in tidal front lines are probably incorrect.

The physical basis for the larval distribution observed in the present study is not clear. The simplest explanation postulates a greater abundance of larvae below the pycnocline for reasons unrelated to the presence or absence of tidal fronts. In support of this are considerable data showing the deep distribution of advanced zoeal stages of many estuarine species of crab (Sandifer 1975). Such larvae would be unaffected by the convergent frontal circulation occurring above them. But early stage zoea are usually more abundant 
closer to the surface (Dittel \& Epifanio 1982), and replicated observations at our non-frontal site showed both high abundance ( $>50$ zoeae $\mathrm{m}^{-3}$ ) and uniform distribution in the upper $5 \mathrm{~m}$ of the water column.

Thus it appears that the distribution of crab larvae near tidal fronts is to some degree controlled by the convergent frontal circulation. In an earlier paper (Epifanio 1987), we proposed a physical model for concentrating larvae at the surface on the light-water side of a tidal front, but that model was based on surface sampling (no data were collected on larval abundance below the pycnocline) of only one front. In the present study, replicated observations at the ebb-tide site suggest that larval abundance was generally higher in the heavier water on the southwest side of that front (Fig. 2). Frontal circulation appears to have modified this initial pattern and to have concentrated larvae below the pycnocline. Because downwelling velocity decreases with depth-specific balance between larval swimming rate and downwelling velocity. In support of this idea, there is ample evidence for upward swimming of crab larvae under the type of downwelling conditions occurring at tidal fronts (Sulkin 1984).

Regardless of the apparent concentration of larvae by frontal circulation, and any ecological effects (e.g. dispersal/retention, food availability, predation) are bound to be mitigated by the ephemeral nature of the fronts. Both aerial and surface observations shows that these fronts dissipate within a hour after each change of tide. Associated larvae are then subjected to tidal mixing for ca $6 \mathrm{~h}$ until another front begins to form. Thus the chance of a given patch of larvae being entrained in the same front on consecutive tidal cycles is small. Nevertheless, that patch may be entrained in another front on a subsequent tidal cycle, and any one patch could be entrained in several fronts during its entire period of larval development. Certainly this concentration of larvae at fronts would help maintain patch integrity, even if the patch were entrained only a few times during its existence. Because the adult forms of the most abundant taxa collected in this study (Pinnixa spp., Xanthidae) have limited mobility, maintenance of patches of larvae until settlement may be important in recruitment of adequate numbers of juveniles to suitable adult habitat. Thus any physical mechanism that reduces dispersion of patches may be consequential to the success of these species.

Acknowledgements. This study was supported by funds from the Marine Biology-Biochemistry Program of College of Marine Studies and by a grant from the Wallops-Breaux Program of the U.S. Fish \& Wildlife Service. The grant was administered by the Delaware Department of Natural Resources \& Environmental Control. Field assistance was provided by Scott Combs, Pete Rowe, and Big John Ellsworth. Richard Garvine and Larry Curtis provided helpful criticisms of the manuscript.

\section{LITERATURE CITED}

Bowman, M. J., Iverson, R. L. (1978). Estuarine and plume fronts. In: Bowman, M. J., Esaias, W. E. (eds.) Oceanic fronts in coastal proces. Springer-Verlag, New York, p. $87-105$

Chin-Leo, G. (1985). Some factors determining the distribution of the dinoflagellate, Heterocapsa triquetra in the Potomac and Chesapeake Estuaries. M. S. thesis. Univ. of Delaware, Newark

Dittel, A., Epifanio, C. E. (1982). Seasonal abundance and vertical distribution of crab larvae in Delaware Bay. Estuaries 5: 197-202

Epifanio, C. E. (1987). The role of tidal fronts in maintaining patches of brachyuran zoeae in estuarine waters. J. crust. Biol. 7. 513-517

Epifanio, C. E. (1988). Transport of crab larvae between estuaries and the continental shelf. In: Jansson, B. O. (ed.) Lecture notes on coastal and estuarine studies. Vol. 22. Springer-Verlag, New York, p. 291-305

Fournier, R. O., van Det, M., Wilson, J. S., Hargraves, N. B. (1979). Influence of the shelf-break front off Nova Scotia on phytoplankton standing stock in winter. J. Fish. Res. Bd Can. 36: 1228-1237

Garvine, R. W. (1974). Dynamics of small scale oceanic fronts. J. phys. Oceanogr. 4: 557-569

Garvine, R. W., Monk, J. D. (1974). Frontal structure of a river plume. J. geophys. Res. 79: 2251-2259

Huzzy, L. M., Brubaker, J. M. (1988). The formation of longitudinal fronts in a coastal plain estuary. J. geophys. Res. 93: 1329-1334

Klemas, V., Polis, D. F. (1977). A study of density fronts and their effects on coastal pollutants. Rem. Sens. Env. 6: 95-126

Knauss, J. A. (1978). Introduction to physical oceanography. Prentice-Hall. Englewood Cliffs, NJ

Pingree, R. D., Bowman, M. J., Esaias, W. E. (1978). Headland fronts. In: Bowman, M. J., Esaias, W. E. (eds.) Oceanic fronts in coastal proces. Springer-Verlag, New York. p. $78-86$

Pingree, R. D., Forster, G. R., Morrison, G. K. (1974). Turbulent convergent tidal fronts. J. mar. biol. Ass. U.K. 54 : $469-479$

Pingree, R. D., Holligan, P. M., Mardell, G. T., Head, R. N. (1976). The influence of physical stability on spring, summer, and autumn phytoplankton blooms in the Celtic Sea. J. mar biol. Ass. U. K. 56: 845-873

Sandifer, P. A. (1975). The role of pelagic larvae in recruitment to populations of adult decapod crusttaceans in the York River estuary and adjacent lower Chesapeake Bay, Va. Estuar. coast. Mar. Sci. 3: 269-279

Sarabun, C. C. (1980). Structure and formation of Delaware Bay fronts. Doctoral dissertation, Univ. of Delaware, Newark

Sick, L. V., Johnson, C. C., Engel, R. (1978). Trace metal enhancement in the biotic and abiotic components of an estuarine tidal front. J. geophys. Res. 83: 4659-4667

Simpson, J. H., Hunter, J. H. (1974). Fronts in the irish sea. Nature, Lond. 250: 404-406

Sokal, R. R., Rohlf, F. J. (1981). Biometry, 2nd edn. W. H. Freeman and Co., New York

Sulkin, S. D. (1984). Behavioral basis of depth regulation in the larvae of brachyuran crabs. Mar Ecol. Prog. Ser. 15: $181-205$

Tyler, M. A., Coats, D. W., Anderson, D. M. (1982). Encystment in a dynamic environment: deposition of dinoflagel- 
late cysts by a frontal convergence. Mar. Ecol. Prog. Ser. 7 $163-178$

Tyler, M. A., Seliger, H. H. (1978). Annual subsurface transport of a red tide dinoflagellate to its bloom area: water circulation patterns and organisms distributions in the Chesapeake Bay. Limnol. Oceanogr. 23: 227-246

This article was submitted to the editor
Zar, J. H. (1984). Biostatistical analysis, 2nd edn. Prentice-Hall Inc, Englewood Cliffs, NJ

Zeldis, J. R., Jillett, J. B. (1982). Aggregation of pelagic Munida gregaria (Fabricius) (Decapoda, Anomura) by coastal fronts and internal waves. J. Plankton Res. 4: $839-857$

Manuscript first received: December 7, 1988

Revised version accepted: April 2, 1989 